\title{
Power Distribution in the Basque Parliament using Games with Externalities
}

\author{
G. Arévalo-Iglesias ${ }^{1}$ and M. Álvarez-Mozos ${ }^{2}$ \\ ${ }^{1}$ Deptartamento de Estatística, Análise Matemática e Optimización, Universidade de Santiago de \\ Compostela, Spain. \\ ${ }^{2}$ Departament de Matemàtica Econòmica, Financera i Actuarial and BEAT, Universitat de \\ Barcelona, Spain.
}

Published in Theory and Decision (2020)

Published version available at http://www.sciencedirect.com/

DOI: $10.1007 / \mathrm{s} 11238-020-09748-2$

\begin{abstract}
In this paper we study the distribution of power in the Basque Parliament since the restoration of the Spanish democracy. The classic simple games do not fit with the particular voting rule that it is used to invest the president of the regional government. In order to model this voting mechanism we incorporate coalitional externalities to the game. We use the extensions of the most popular power indices to games with externalities that have been proposed in the most recent literature. Moreover, we propose a method to estimate the probability of a given coalition based on the ideological positions of its members in a two-dimensional political spectrum.
\end{abstract}

Keywords Power indices; Simple games; Externalities; Plurality rule

\section{Introduction}

Power indices and other related game theoretical tools are very useful to study the power distribution in decision making bodies. For instance, Laruelle and Widgrén (1998) analyze 
the decision making mechanism in the EU Council of Ministers, ${ }^{1}$ Alonso-Meijide and Bowles (2005) develop algorithms to examine how power is shared in the IMF, and Huber et al. (2003) use power indices to study the fiscal policy in the OCDE countries. All these examples model the decision making procedure by a simple cooperative game with transferable utility, classic game henceforth. Such games are defined by characteristic functions that attach to every possible coalition of agents a worth equal to zero or one ( 0 to losing coalitions and 1 to the winning ones), are monotonic (if a coalition grows its worth cannot decrease), and there is at least one winning coalition. This classic model is suitable when the decisions to be made are dichotomous, usually whether to pass a bill or not. In the literature, a variety of power indices have been proposed for this kind of game. The most popular ones are the Shapley-Shubik index (Shapley and Shubik, 1954) and the Banzhaf index (Banzhaf, 1964), ${ }^{2}$ both based on the winning coalitions for which an agent's participation is crucial. Other indices are based on minimal winning coalitions for which the participation of every member is critical, like the Deegan-Packel index (Deegan and Packel, 1978) or the Public good index (Holler, 1982).

The Basque Parliament (Legebiltzarra) uses the plurality rule to elect the president of the autonomous regional government (Lehendakari). First, every political group with representation in the chamber has the right to propose a candidate. Then, every deputy must vote in favor of one of the candidates or otherwise abstain, that is, voting against is not allowed. To be appointed Lehendakari in the first ballot, it is necessary that a majority of the chamber votes in favor. If no candidate fulfills this requirement, a second ballot takes place 24 hours later, and this time it is enough to get more votes than any other candidate in order to be elected. ${ }^{3}$ This voting procedure is not dichotomous because it is intended to choose among many potential candidates. Consequently, classic games are not appropriate and richer models need to be employed. Games with coalitional externalities, as introduced by Thrall and Lucas (1963), provide a convenient framework to model voting procedures that are based on the plurality rule. These games are defined by partition functions that describe the worth of every embedded coalition, which consists of a coalition of agents and an organization of the rest of agents. They describe situations in which the formation of one coalition can influence the worth of another coalition.

Recently, the study of games with coalitional externalities has attracted the attention

\footnotetext{
${ }^{1}$ With the Maastricht Treaty, that is, before the enlargement to eastern Europe.

${ }^{2}$ This index was actually first proposed by Penrose (1946) but it is most widely known after Banzhaf's work.

${ }^{3}$ Other institutions with similar investiture procedures in Spain are the Parliament of Asturias and the City Councils.
} 
of many researchers (Maskin, 2016) and important contributions have been made (see for instance de Clippel and Serrano, 2008; Macho-Stadler et al., 2007). Here, we use two power indices introduced in the aforesaid contributions that generalize the Shapley-Shubik index, ${ }^{4}$ another that extends the Banzhaf index introduced by Álvarez-Mozos and Tejada (2015), and the generalizations of the Deegan-Packel and Public good indices defined in Alonso-Meijide et al. (2017a). We use them to study the distribution of power in Legebiltzarra since 1984. Here we present the main features of the complete study that can be found in Arévalo-Iglesias (2018).

The Basque political system is quite particular compared to other regions of Spain. It is much more fragmented and there are a high number of potentially influential parties in the chamber. It is generally assumed that the political competition occurs along two fundamental cleavages: The centre-periphery dimension and the left-right dimension ${ }^{5}$ (Leonisio and Strijbis, 2014). Even though some authors (Gillespie, 2000; Leonisio, 2012) think that the centre-periphery dimension dominates the Basque political system, and some others (Albertos, 2002; De la Calle Robles, 2005) think the opposite, they all agree that these are the two major dimensions that vertebrate the political competition. We propose a method to estimate the probability of a coalition to emerge using real data about the ideological positions of the parties along these cleavages. In summon, the above described voting procedure, the high fragmentation, and the number of competing parties lead to very interesting situations to be analyzed.

In Section 2 we introduce the models and power indices, explaining in each case the classic approach and the way in which externalities are incorporated to it. In Section 3 we study the power distribution in the Basque Parliament applying these indices. Section 4 concludes by drawing some conclusions from our analysis.

\footnotetext{
${ }^{4}$ To be precise, we use their specification to simple games with externalities as defined in Alonso-Meijide et al. (2017a).

${ }^{5}$ While the centre-periphery dimension is clearly referred to the nationalist issue, it is not so clear that the left-right dimension corresponds only with the economic issue, as some authors (Knutsen, 1995; Van der Eijk et al., 2005) define this cleavage as a super-issue that includes several other dimensions such as the religious-secular issue or the materalist/post-materialist values.
} 


\section{Simple games with externalities and power indices}

A decision making body is described by a set of agents $N$ together with a collection of winning coalitions $W \subseteq\{S: S \subseteq N, S \neq \emptyset\}$. A classic simple game on the player set $N$ is defined by a characteristic function $v$ where $v(S)=1$ if $S \in W$ and $v(S)=0$ if $S \notin W$. Any sensible voting procedure gives rise to a monotonic game. That is, $v(S) \leq v(T)$ for every $S \subseteq T$.

The most common voting procedure in a parliament is a majority rule. Classic simple games are appropriate when voting by majority, either simple or qualified, because whether a coalition is winning or loosing only depends on the coalition itself. However, this is not the case for voting mechanisms that use the plurality rule, like an investiture procedure that allows the emergence of a minority government if the parties in the opposition do not agree on another alternative. In these cases, whether a coalition is winning or loosing depends also on the rest of coalitions because the required majority is just relative. These situations can be considered by incorporating externalities to classic games (Thrall and Lucas, 1963).

Let $\mathcal{P}(N)$ denote the set of partitions of the finite set $N .{ }^{6}$ An embedded coalition is a pair $(S, P)$ where $S \subseteq N$ and $P \in \mathcal{P}(N)$ such that $S \in P$. We denote by $E C^{N}$ the set of embedded coalitions of $N$. A game with externalities on the player set $N$ is defined by a partition function $v: E C^{N} \rightarrow \mathbb{R}$ such that $v(\emptyset, P)=0$ for every $P \in \mathcal{P}(N)$. For every $(S, P) \in E C^{N}, v(S, P)$ describes the worth of a coalition $S$ when the coalition structure $P$ forms. A simple game with externalities on the player set $N$ (Alonso-Meijide et al., 2017a) is defined by a partition function $v$ satisfying three conditions. First, $v$ is a $\{0,1\}$-valued function. Second, it is a monotonic function with respect to the partial order defined in Alonso-Meijide et al. (2017b) by

$$
(S, P) \subseteq(T, Q) \Longleftrightarrow S \subseteq T \text { and } \forall T^{\prime} \in Q \backslash\{T\}, \exists S^{\prime} \in P \text { such that } T^{\prime} \subseteq S^{\prime}
$$

Then, $v$ is a monotonic partition function if $v(S, P) \leq v(T, Q)$ for every $(S, P),(T, Q) \in E C^{N}$ such that $(S, P) \subseteq(T, Q)$. Third, there is at least one embedded coalition whose worth is equal to 1.

Simple games with externalities fit very well with voting procedures based on the plurality rule, like the ones described above. Let $(S, P) \in E C^{N}$. The partition structure $P$ describes the coalitions that support the different candidates. Then, $v(S, P)=1$ means that $S$ is the coalition with most votes among the coalitions in $P$ and we say that $(S, P)$ is a winning

\footnotetext{
${ }^{6}$ We consider that the empty set is an element of every partition.
} 
embedded coalition. Similarly, $v(S, P)=0$ means that $S$ is not the coalition with most votes among the coalitions in $P$ and we say that $(S, P)$ is a loosing embedded coalition. The monotonicity condition can be understood as follows. If $(S, P)$ is a winning embedded coalition, then it will remain winning if $S$ itself grows and also if the rest of coalitions in $P$ become more divided. Finally, the third condition implies that $(N,\{N, \emptyset\})$ must be a winning embedded coalition.

Since the real instances that we study have too many players to describe them in detail, here we present a simple example for illustrative purposes.

Example 2.1 Consider a Parliament with four parties, $N=\{1,2,3,4\}$, and the following set distribution: $\left(w_{1}, w_{2}, w_{3}, w_{4}\right)=(13,7,5,2)$. Suppose also that the voting procedure is the plurality rule. As there are no ties, for every partition of the player set there is one winning embedded coalition. More precisely, for every $P \in \mathcal{P}(N)$, let $S \in P$ be such that $\sum_{i \in S} w_{i}>\sum_{i \in T} w_{i}$ for every $T \in P$ with $T \neq S$. Then, $v(S ; P)=1$ and $v(T ; P)=0$ for every $T \in P$ with $T \neq S$. Below, we list all winning embedded coalitions omitting braces.

$$
\begin{aligned}
& (N ; N), \\
& (123 ; 123,4),(124 ; 124,3),(134 ; 134,2),(234 ; 1,234), \\
& (12 ; 12,34),(13 ; 13,24),(14 ; 14,2,3),(12 ; 12,3,4),(13 ; 13,2,4),(14 ; 14,2,3), \\
& (1 ; 1,23,4),(1 ; 1,24,3),(1 ; 1,2,34),(1 ; 1,2,3,4) .
\end{aligned}
$$

That is, the simple game with externalities is described by the partition function that assigns 1 to these embedded coalitions and 0 to the rest.

\subsection{Shapley-Shubik indices}

Shapley and Shubik (1954) proposed a way to measure how decisive are the players in a classic simple game. The Shapley-Shubik power index is obtained by applying the Shapley value, the popular solution concept introduced in Shapley (1953) for general classic games, to a classic simple game. Let $\Pi^{N}$ denote the set of permutations or orderings of the finite set $N=\{1, \ldots, n\}$. Given $\pi \in \Pi^{N}, \pi(i)$ describes the position of player $i$ at $\pi$. The Shapley-Shubik index of player $i \in N$ in a classic simple game is defined by

$$
S h_{i}(v)=\frac{1}{\left|\Pi^{N}\right|} \sum_{\pi \in \Pi^{N}} v(\{j: \pi(j) \leq \pi(i)\})-v(\{j: \pi(j)<\pi(i)\}),
$$


where $v$ is the characteristic function of the game. In other words, it is the average marginal contribution of a player to its set of predecessors at any possible ordering. This power index can also be described using the winning coalitions for which the participation of a player is critical. Let $P_{i}=\{S \in W: S \backslash\{i\} \notin W\}$, the Shapley-Shubik index of player $i \in N$ can be obtained from the following expression

$$
S h_{i}(v)=\sum_{S \in P_{i}} \frac{(|S|-1) !(|N|-|S|) !}{|N| !} .
$$

The above expression shows that the Shapley-Shubik index is a measure of decisiveness. The index has also a nice probabilistic interpretation (Straffin, 1988). Assume that $p_{i}$ is the probability that player $i$ votes in favor of a bill and that this probability follows a uniform distribution on $[0,1]$. Then, the Shapley-Shubik index is the probability of player $i$ 's vote to change the result under the homogeneity assumption, i.e., if $p_{i}=p$ for every $i \in N$.

In what follows, we present two different extensions of this index to games with externalities.

\section{The Externality-free index}

de Clippel and Serrano (2008) introduced the Externality-free value of player $i \in N$ in a game with externalities by

$$
S h_{i}^{E F}(v)=S h_{i}\left(v^{*}\right),
$$

where $v$ is the partition function of the game and $v^{*}$ is an associated characteristic function defined for every $S \subseteq N$ by $v^{*}(S)=v\left(S,\left\{S,\{j\}_{j \in N \backslash S}\right\}\right)$. The general purpose of the authors is to extend the axiomatic characterization of Young (1985) to games with externalities. Therefore, they address the non-trivial problem of generalizing the concept of a marginal contribution to situations with externalities. When a player $i$ leaves a coalition $S$ to join another one of the structure $T \in P$ with $T \neq S$, two different effects are considered. The first, the so-called intrinsic marginal contribution, is the change in the worth of $S$ when player $i$ leaves it to remain alone. The second, is the externality effect created on $S \backslash\{i\}$ by player $i$ joining coalition $T$. Then, $S h_{i}^{E F}$ is characterized based on a monotonicity axiom that pays attention only to the intrinsic marginal contribution. Here we call it Externality-free index (see Álvarez-Mozos et al., 2017) because we only apply it to simple games with externalities. 


\section{Average index}

Macho-Stadler et al. (2007) extended the Shapley value to games with externalities following an average approach. First, the partition function is transformed into a characteristic function using a probability distribution. For every $(S, P) \in E C^{N}$, let $\alpha(S, P) \in \mathbb{R}_{+}$be $^{7}$ such that $\sum_{P \in \mathcal{P}(N): S \in P} \alpha(S, P)=1$. Then, the average classic game is defined for every $S \subseteq N$ by

$$
v^{\alpha}(S)=\sum_{P \in \mathcal{P}(N): S \in P} \alpha(S, P) v(S, P) .
$$

Second, the Shapley value of this average classic game is computed. The authors study this family of Shapley values and characterize it by extending Shapley's original axioms.

Macho-Stadler et al. (2007) also propose a particular value of this family, obtained by taking $\alpha^{A}(S, P)=\frac{\prod_{T \in P \backslash\{S\}}(|T|-1) !}{(|N|-|S|) !}$. We refer to it as the Average index. ${ }^{8}$ The Average index of player $i$ in a game with externalities is

$$
S h_{i}^{A}(v)=\sum_{(S, P) \in E C^{N}} \frac{\prod_{T \in P \backslash\{S\}}(|T|-1) !}{(|N|-|S|) !} \beta_{i}(S) v(S, P),
$$

where $v$ is the partition function and $\beta_{i}(S)$ is defined for every $S \subseteq N$ by $\beta_{i}(S)=\frac{(|S|-1) !(|N|-|S|) !}{|N| !}$ if $i \in S$ and $\beta_{i}(S)=-\frac{|S| !(|N|-|S|-1) !}{|N| !}$ if $i \notin S$.

\subsection{The Banzhaf index}

Banzhaf (1964) proposed an alternative way to measure the decisiveness of a player in a classic simple game. The Banzhaf index of player $i \in N$ in a classic game is defined by

$$
B a_{i}(v)=\frac{1}{2^{|N|-1}} \sum_{S \subseteq N \backslash\{i\}} v(S \cup\{i\})-v(S) .
$$

When applied to simple classic games, it can be described by

$$
B a_{i}(v)=\frac{\left|P_{i}\right|}{2^{|N|-1}} .
$$

That is, the Banzhaf index of player $i$ is the probability that the player is decisive for a coalition assuming that all coalitions are equally likely. As the Shapley-Shubik index, it

\footnotetext{
${ }^{7}$ Where $\mathbb{R}_{+}=\{x \in \mathbb{R}: x \geq 0\}$

${ }^{8}$ Index instead of value because we only apply it to simple games with externalities.
} 
has an alternative probabilistic interpretation (Straffin, 1988). If $p_{i}$ is the probability that player $i$ votes in favor of a bill and this probability follows a uniform distribution on $[0,1]$, then the Banzhaf index is the probability of player $i$ 's vote to change the result under the independence assumption, i.e., if $p_{i}$ and $p_{j}$ are independent for every $i \neq j$.

\section{$\Lambda$-Banzaf value}

Álvarez-Mozos and Tejada (2015) suggested two generalizations of the Banzhaf index to games with externalities using also an average approach like Macho-Stadler et al. (2007). That is, using collections of probability distributions over the set of coalition structures that can arise. Here, we focus on the first one: The $\Lambda$-Banzhaf index.

Let $\Omega$ be the set, possibly infinite, of all potential players. For every finite set of players, $N \subseteq \Omega$, let $\lambda^{N}: E C^{N} \rightarrow \mathbb{R}_{+}$be a mapping such that for every $S \subseteq N, \sum_{P \in \mathcal{P}(N): S \in P} \lambda^{N}(S, P)=$ 1. In other words, $\lambda^{N}$ provides probability distributions over the coalition structures that can arise in $N \backslash S$ for every possible coalition $S$. We denote by $\Lambda=\left\{\lambda^{N}: N \subseteq \Omega\right\}$ the collections of probability distributions, one for each possible finite player set $N \subseteq \Omega$. Let $\mathcal{L}$ be the set of $\Lambda$-s that are consistent in the following sense. First, for every $N, N^{\prime} \subseteq \Omega$ and $(S, P),\left(S^{\prime}, P^{\prime}\right) \in E C^{N}$ such that $P \backslash\{S\}=P^{\prime} \backslash\left\{S^{\prime}\right\}, \lambda^{N}(S, P)=\lambda^{N^{\prime}}\left(S^{\prime}, P^{\prime}\right)$. Second, for

every $N \subseteq \Omega$ and $(S, P) \in E C^{N \backslash\{j\}}, \lambda^{N \backslash\{j\}}(S, P)=\sum_{T \in P \backslash\{S\}} \lambda^{N}(S, P \backslash\{T\} \cup\{T \cup\{j\}\})$. Finally, given $\Lambda \in \mathcal{L}, N \subseteq \Omega$ and a partition function $v$, the expected worth of coalition $S$ is described by

$$
v^{\Lambda}(S)=\sum_{P \in \mathcal{P}(N): S \in P} \lambda^{N}(S, P) v(S, P) .
$$

The $\Lambda$-Banzhaf index of player $i \in N$ is obtained applying the Banzhaf index to the characteristic function $v^{\Lambda}$

$$
B a_{i}^{\Lambda}(v)=B a_{i}\left(v^{\Lambda}\right)
$$

\subsection{The Deegan-Packel and Public good indices}

The Deegan-Packel (Deegan and Packel, 1978) and Public good (Holler, 1982) indices for classic simple games are based on the idea that only minimal winning coalitions matter when it comes to assess the power of agents. A winning coalition is minimal if all of its members are critical. Then, compared to the Shapley-Shubik or Banzhaf indices they are based in less 
coalitions. The Deegan-Packel and Public good indices of player $i \in N$ in a classic simple game are defined by

$$
\begin{aligned}
& D P_{i}(v)=\frac{1}{|M|} \sum_{S \in M_{i}} \frac{1}{|S|} \text { and } \\
& P G_{i}(v)=\frac{\left|M_{i}\right|}{\sum_{j=1}^{n}\left|M_{j}\right|},
\end{aligned}
$$

where $M=\{S \in W: \forall T \subsetneq S, T \notin W\}$ is the set of minimal winning coalitions and $M_{i}=$ $\{S \in M: i \in S\}$ is the set of the ones in which player $i$ participates.

On the one hand, the Deegan-Packel index shares the power equally among the minimal winning coalitions and then also equally among the members of each coalition. On the other hand, the Public good index assigns power proportionally to the number of minimal winning coalitions in which each player participates.

\section{DP-Index and PG-Index}

Alonso-Meijide et al. (2017a) suggest two very natural generalizations of these power indices to simple games with externalities. The idea is to use minimal winning embedded coalitions instead of minimal winning coalitions. A winning embedded coalition is minimal if it does not contain any other winning embedded coalition with the inclusion relation defined in Equation (1). Let $\mathcal{M}(v)$ be the set of minimal winning embedded coalitions of the simple game with externalities, this is, $\mathcal{M}(v)=\{v(S, P)=1: \forall(T, Q) \subsetneq(S, P), v(T, Q)=0\}$. Let also $\mathcal{M}_{i}(v)$ denote the set of minimal winning embedded coalitions that contain a given player $i$, i.e., $\mathcal{M}_{i}(v)=\{(S, P) \in \mathcal{M}(v): i \in S\}$. The extensions of the Deegan-Packel and Public good indices ${ }^{9}$ are defined for every $i \in N$ by

$$
\begin{aligned}
D P_{i}^{A A F}(v) & =\frac{1}{|\mathcal{M}(v)|} \sum_{(S, P) \in \mathcal{M}_{i}(v)} \frac{1}{|S|} \quad \text { and } \\
P G_{i}^{A A F}(v) & =\frac{\left|\mathcal{M}_{i}(v)\right|}{\sum_{j \in N}\left|\mathcal{M}_{j}(v)\right|} .
\end{aligned}
$$

\footnotetext{
${ }^{9}$ We refer to them as DP-Index and PG-Index.
} 


\subsection{Axiomatic foundation}

Even if the aim of this paper is not theoretical but rather applied, we include here a brief comparison of the power indices introduced so far from an axiomatic viewpoint. We begin with the classic power indices and then, we discuss the generalizations of the properties they satisfy to situations with externalities.

There are two properties that are shared by all the classic indices that we consider here, symmetry and the null player property. Symmetry is an equal treatment of equals property, which states that two players who can be exchanged with no impact in any situation should have the same power. ${ }^{10}$ The null player property states that if an agent's participation in a coalition never makes a difference, then it should be allocated no power (Dubey and Shapley, 1979). A property that distinguishes the Banzhaf index from the rest is efficiency. In general, it does not share one unit of power among the players. Nonetheless, the Banzhaf index satisfies interesting collusion properties (Haller, 1994), i.e., it is independent to the collusion of two players into one. Finally, the power indices based on minimal winning coalitions, presented in Section 2.3, are different from the rest as they are not additive (or linear). More precisely, they do not satisfy the transfer property (see Dubey, 1975), which is a variant of additivity used in many axiomatizations of power indices. To pin down each of these indices Deegan and Packel (1978) and Holler and Packel (1983) consider some weighted variants of the transfer property. ${ }^{11}$

Some of the classic properties can be extended quite naturally to the framework of simple games with externalities. For instance, efficiency, symmetry, and the transfer property (see Álvarez-Mozos et al., 2017) but also the properties used to axiomatize the Deegan-Packel and Public good indices have rather obvious generalizations (Alonso-Meijide et al., 2017a). Álvarez-Mozos and Tejada (2015) also use natural generalizations of the properties used by Casajus (2012) to characterize the $\Lambda$-Banzhaf value. The null player property however, has at least two possible extensions to games with externalities (see, for instance de Clippel and Serrano, 2008). They differ in the situations that are considered to determine null players. The Externality-free index satisfies both extensions whereas the Average index satisfies only the weakest one (Macho-Stadler et al., 2007).

\footnotetext{
${ }^{10}$ In most axiomatic characterizations symmetry can be replaced by anonymity (a stronger property) that requires the power to be independent to the labeling of the players (see, for instance Shapley, 1953).

${ }^{11}$ Or alternatively, weighted versions of the monotonicity property (Young, 1985).
} 


\section{Results}

In this section we apply the indices presented in Section 2 to a real legislature in which externalities play a role: The Basque Parliament or Legelbitzarra. To begin with, we depict in Table 1 the seat distribution in Legebiltzarra since $1984 .^{12}$

\begin{tabular}{|c|c|c|c|c|c|c|c|}
\hline \multirow{3}{*}{$\begin{array}{c}\text { Term of office } \\
1984\end{array}$} & \multicolumn{7}{|c|}{ Parties and seats } \\
\hline & EAJ-PNV & PSE & $\mathrm{HB}$ & $\mathrm{AP}$ & $\mathrm{EE}$ & & \\
\hline & 32 & 19 & 11 & 7 & 6 & & \\
\hline \multirow{2}{*}{1986} & PSE & EAJ-PNV & $\mathrm{HB}$ & $\mathrm{EA}$ & $\mathrm{EE}$ & $\mathrm{AP}$ & CDS \\
\hline & 19 & 17 & 13 & 13 & 9 & 2 & 2 \\
\hline \multirow{2}{*}{1990} & EAJ-PNV & PSE & $\mathrm{HB}$ & $\mathrm{EA}$ & $\mathrm{PP}$ & $\mathrm{EE}$ & $\mathrm{UA}$ \\
\hline & 22 & 16 & 13 & 9 & 6 & 6 & 3 \\
\hline \multirow{2}{*}{1994} & EAJ-PNV & PSE-EE & $\mathrm{HB}$ & $\mathrm{PP}$ & $\mathrm{EA}$ & IU-EB & $\mathrm{UA}$ \\
\hline & 22 & 12 & 11 & 11 & 8 & 6 & 5 \\
\hline \multirow{2}{*}{1998} & EAJ-PNV & $\mathrm{PP}$ & PSE-EE & $\mathrm{EH}$ & EA & IU-EB & UA \\
\hline & 21 & 16 & 14 & 14 & 6 & 2 & 2 \\
\hline \multirow{2}{*}{2001} & EAJ-PNV & PP & PSE-EE & EA & $\mathrm{EH}$ & IU-EB & \\
\hline & 25 & 19 & 13 & 8 & 7 & 3 & \\
\hline \multirow{2}{*}{2005} & EAJ-PNV & PSE-EE & $\mathrm{PP}$ & PCTV & $\mathrm{EA}$ & IU-EB & Aralar \\
\hline & 21 & 18 & 15 & 9 & 8 & 3 & 1 \\
\hline \multirow{2}{*}{2009} & EAJ-PNV & PSE-EE & $\mathrm{PP}$ & Aralar & $\mathrm{EBB}$ & $\mathrm{EA}$ & UPyD \\
\hline & 30 & 25 & 13 & 4 & 1 & 1 & 1 \\
\hline \multirow{2}{*}{2012} & EAJ-PNV & EH-Bildu & PSE-EE & $\mathrm{PP}$ & UPyD & & \\
\hline & 27 & 21 & 16 & 10 & 1 & & \\
\hline \multirow{2}{*}{2016} & EAJ-PNV & EH-Bildu & Podemos & PSE-EE & PP & & \\
\hline & 28 & 18 & 11 & 9 & 9 & & \\
\hline
\end{tabular}

Table 1: Composition of the Basque Parliament 1984-2016

To better understand Table 1 it is important to point out that the Basque political system is determined by two cleavages, the left-right and the centre-periphery. We can find potentially influential parties in the 4 corners of the board: left-periphery ( $\mathrm{HB}$, EE, EH, PCTV, Aralar, EH-Bildu), right-periphery (EAJ-PNV, EA), left-centre (PSE, IU-EB,

\footnotetext{
${ }^{12}$ We have omitted the results of the 1980 election (the first after the Spanish transition to democracy) because the use of the plurality rule in the investiture procedure began in the 1984 election.
} 
Podemos) and right-centre (AP/PP, CDS, UA). The acronyms in the table stand for: Eusko Alderdi Jeltzalea-Partido Nacionalista Vasco (EAJ-PNV), Partido Socialista de Euskadi (PSE), Herri Batasuna (HB), Alianza Popular (AP), Euskadiko Ezkerra (EE), Eusko Alkartasuna (EA), Centro Democrático Social (CDS), Partido Popular (PP), Unidad Alavesa (UA), Izquierda Unida-Ezker Batua (IU-EB), Euskal Herritarrok (EH), Ezker Batua-Berdeak (EBB), Unión Progreso y Democracia (UPyD) and Euskal Herria Bildu (EH Bildu). For further information about the history and ideology of the parties in this table see Ansolabehere and Puy (2015).

We have computed the five power indices presented before in the simple games with externalities associated with the 10 legislatures that are shown in the table. We examine the results in two ways. First, we analyze the power distribution in some representative legislatures. Second, we study the evolution of the results for the political forces that, in our opinion, are representative of each corner of the Basque political board.

Before we perform the analysis, it is necessary to introduce some notions about the interpretation of the indices and the computation of the $\Lambda$-Banzhaf index.

\section{On the interpretation of the indices and the selection of $\Lambda$}

We consider 5 different power indices, 4 of which meet the efficiency property: The Externalityfree index, the Average index, the DP-Index and the PG-Index. Moreover, all of the 5 indices return values bounded between 0 and 1 . Thereby, there are 4 indices which are efficient and $[0,1]$ bounded. The interpretation of these indices will be easy as they can be understood as the proportion of power that each party holds in the chamber.

For the other index, the $\Lambda$-Banzhaf index, the frame becomes a little bit more diffuse, since the results cannot be interpreted as shares of power. To solve this problem, we have decided to normalize the $\Lambda$-Banzhaf index in this work. The resulting power index is denoted by $\Lambda$-Banzhaf N. ${ }^{13}$

Moreover, as shown in Section 2.2, for the computation of this last index it is necessary to define a family of probability distributions $\Lambda=\left\{\lambda^{N}: N \subseteq \Omega\right\} \in \mathcal{L}$ that is consistent. ÁlvarezMozos and Tejada (2015) propose a variety of such families. Based on one of them we

\footnotetext{
${ }^{13}$ It is worth to point out that the normalized version of the Banzhaf index losses some important properties of the original index like the transfer property described in Section 2.4.
} 
suggest a method to introduce the ideology of the parties that make up the chamber into the probability distributions that lead to the computation of the index.

The family of probability distributions proposed by the authors, denoted by $\Lambda^{p}$, is defined for each partition of the player set, $P \in \mathcal{P}(N)$, and each embedded coalition $(S, P) \in E C^{N}$ by

$$
\lambda^{N}(S, P)= \begin{cases}p & \text { if }(S, P)=(S,\{S, N \backslash S\}) \\ 1-p & \text { if }(S, P)=\left(S,\left\{S,\{i\}_{i \in N \backslash S}\right\}\right) \\ 0 & \text { otherwise }\end{cases}
$$

Thereby, the only problem that remains is the selection of the parameter $p \in(0,1)$. It is in this step that we introduce the ideology of the agents as a main factor to estimate the probabilities of the formation of each embedded coalition. The idea is to define $p$ as the probability that the grand coalition forms in $N$. To estimate such probability we take into account how much likely are the players to collaborate given their ideological differences and similarities. For the evaluation of these differences the cleavages that vertebrate the political arena in the party system under study are of paramount importance.

As we said in the Introduction, it is well known that the Basque political system is structured by two essential cleavages: The left-right dimension and the center-periphery dimension. Accordingly, the probability estimation method is based on these two cleavages. The method is easily adaptable to any desired number of dimensions, though. Let $\mathcal{E}(i) \in$ $[1,10]$ be the position of each player $i \in N$ in the left-right axis, where 1 represents the position further to the left and 10 the one further to the right. In a similar way, let $\mathcal{N}(i) \in[1,10]$ be the position of each player $i \in N$ in the center-periphery axis, where 1 represents the position further to the center and 10 the one further to the periphery. Also, let $\mathcal{D}(i, j)$ be the sum of the absolute differences between the players $i, j$ in the considered cleavages.

The probability that the grand coalition $\{N\}$ forms can be defined as follows: ${ }^{14}$

$$
P(\{N\})=1-\frac{\sum_{i \in N, j \in N, i \neq j} \mathcal{D}(i, j)}{9 c\left(\begin{array}{c}
|N| \\
2
\end{array}\right)}
$$

Where $c$ is the number of cleavages selected, 2 in this case.

\footnotetext{
${ }^{14}$ Please note that in this case we employ the notation $P$ to refer to the probability that an event occurs, not to a partition of the player set $N$.
} 
As a result of this operation we get that the coalition formation is a certain event if there are no ideological differences between the players and that it is an impossible event when those differences are maximum ${ }^{15}$.

We have used this method to obtain the probability distributions $\Lambda$ in this work, but any arbitrary $p \in[0,1]$ may be used instead without loss of validity. In order to apply the method, we needed to locate each party in an ideological spectrum. This operation was done according with the results of the CIS Postelectoral Barometres ${ }^{16}$ for each election, which reflect the way in which citizens locate each party within the two cleavages. The results for the centre-periphery axis were only available starting from the fifth term. For the left-right cleavage results were missing for the fourth and sixth legislatures, and we estimated them using the empirical mean of the results for the previous and next legislatures.

Next, we illustrate this procedure for the most recent legislature under study.

Example 3.1 Since the elections in 2016, five parties (EAJ-PNV, EH-Bildu, Podemos, $P S E-E E$ and $P P)$ are represented in the camera. Figure 1 depicts the ideological positions of the parties according to the corresponding postelectoral barometer.

In Table 2 we describe the distances, $\mathcal{D}(i, j)$, between each pair of parties, $i, j$. Recall that we use the taxicab distance, obtained by adding the distances in each of the two cleavages considered.

\begin{tabular}{cccccc}
\hline \hline $\mathcal{D}(i, j)$ & PNV & EH-Bildu & Podemos & PSE-EE & PP \\
\hline PNV & 0 & 5.03 & 7.12 & 6.33 & 8.85 \\
EH-Bildu & 5.03 & 0 & 4.97 & 8.48 & 13.88 \\
Podemos & 7.12 & 4.97 & 0 & 3.51 & 8.91 \\
PSE-EE & 6.33 & 8.48 & 3.51 & 0 & 5.40 \\
PP & 8.85 & 13.88 & 8.91 & 5.40 & 0 \\
\hline
\end{tabular}

Table 2: Absolute ideological diferences between parties (2016)

Using Equation (3), we obtain the probability that the grand coalition forms in this legislature, $p=P(\{N\})=0.5973333$. This is the $p$ value that we use in Equation (2) to build

\footnotetext{
${ }^{15}$ Given that we are working with differences between pairs, the sum of differences can only be maximum if $N=2$.

${ }^{16}$ Links to the studies: Study 1402 (1984), Study 1565 (1986), Study 1903 (1990), Study 2308 (1998), Study 2421 (2001), Study 2601 (2005), Study 2795 (2009), Study 2964 (2012), Study 3154 (2016). The studies can only be found in spanish.
} 


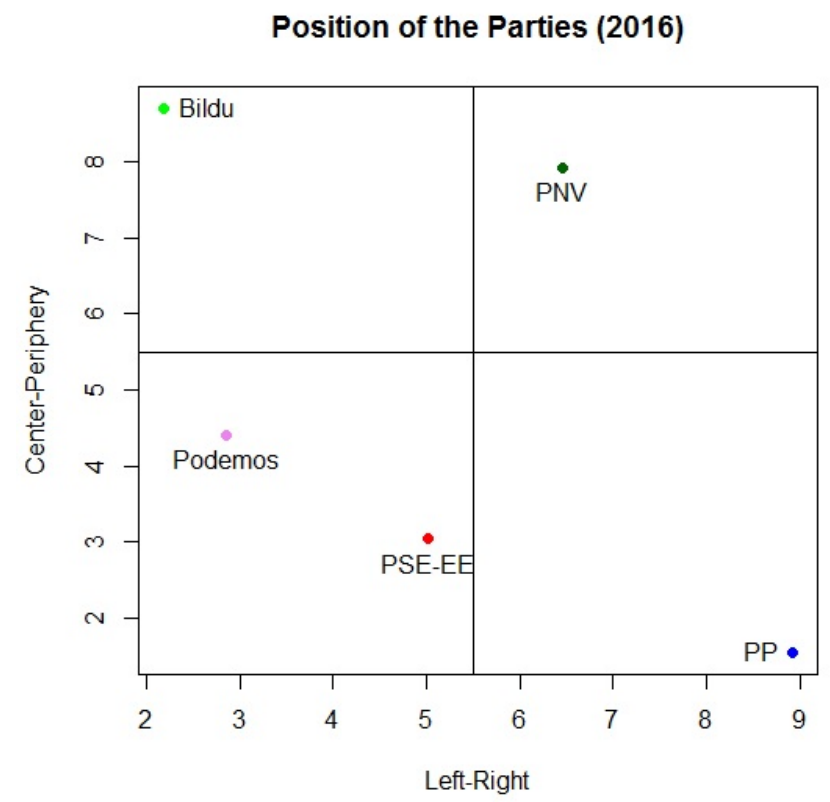

Figure 1: Ideological position of the parties (2016)

the probability distribution for the $\Lambda$-Banzhaf index.

\subsection{Power in the Legebiltzarra}

In this first part of the analysis we focus on 5 out of the 10 analyzed terms of office in order to discover some trends and particularities of the indices. ${ }^{17}$ The interested reader is addressed to Arévalo-Iglesias (2018) where the results of the 10 terms are detailed.

\subsubsection{Legebiltzarra}

In this election only PNV proposed a candidate: Carlos Garaikoetxea, who had already been elected as Lehendakari in the 1980 election, and was reelected due to the favorable vote of $\operatorname{PNV}(32)$ and the abstention of $\operatorname{PSE}(19), \operatorname{AP}(7)$ and EE(6). Herri Batasuna's deputies left the chamber before the voting. The values for the indexes are shown in Table 2.

\footnotetext{
${ }^{17}$ The numerical results have been obtained using the software $\mathrm{R}$. The routines developed are available upon request to the authors.
} 


\begin{tabular}{lccccc}
\hline \hline Index \Party & PNV & PSE & HB & AP & EE \\
\hline EFI & 0.7000 & 0.1167 & 0.1167 & 0.0333 & 0.0333 \\
Average & 0.6500 & 0.1083 & 0.1083 & 0.0667 & 0.0667 \\
$\Lambda$-Banzhaf N & 0.6296 & 0.1112 & 0.1112 & 0.0740 & 0.0740 \\
DPI & 0.6111 & 0.0741 & 0.1296 & 0.0926 & 0.0926 \\
PGI & 0.4375 & 0.1250 & 0.1875 & 0.1250 & 0.1250 \\
\hline Share of seats & 0.4267 & 0.2533 & 0.1467 & 0.0933 & 0.0800 \\
\hline
\end{tabular}

Table 3: Power indices in the 1984 Basque Parliament

This first term brings a 5-player game. This leads to a relatively small set of partitions $\mathcal{P}(N)$ which eases the computational burden. AP and EE are symmetric players in the game with externalities. ${ }^{18}$ It is interesting to note that the notion of symmetry depends on weather externalities are considered or not. It can happen that players are symmetric in the classic game and not in the game with externalities. PSE and HB have the same power according to the indices based on marginal contributions, but not for the ones based on minimal winning embedded coalitions. In fact, PSE gets the same power for the PGI that AP and EE, even when their shares of seats are much smaller. This happens because the sizes of their sets of minimal winning embedded coalitions coincide (are equal to 2).

In political terms we can see that the power is very concentrated in hands of PNV, the largest party. The power indices reflect this fact, as all of them give to PNV a share of power greater than its proportion of seats, and this share is more than a half for all the indices except the PGI. The EFI is the index that gives this party the highest share of power, and the PGI the one that distributes it more. These behaviors set a pattern that continues throughout the rest of legislatures.

\subsubsection{Legebiltzarra}

In 1986 elections two different candidates run for Lehendakari: Jose Antonio Ardanza, from PNV, and Juan Carlos Yoldi, from Herri Batasuna, who was imprisoned in the moment of the voting. Ardanza was appointed Lehendakari with absolute majority in the first ballot with the favorable votes of $\operatorname{PNV}(17), \operatorname{PSE}(19)$ and $\operatorname{CDS}(2)$. It is curious that the party with more seats, PSE, decided to support PNV's candidate instead of proposing its own.

\footnotetext{
${ }^{18}$ Two players are said to be symmetric in a game if swapping them does not change the worth of any (embedded) coalition.
} 


\begin{tabular}{cccccccc}
\hline \hline Index $\backslash$ Party & PSE-EE & PNV & HB & EA & EE & AP & CDS \\
\hline EFI & 0.3929 & 0.1595 & 0.1429 & 0.1429 & 0.1429 & 0.0095 & 0.0095 \\
Average & 0.2737 & 0.2327 & 0.1664 & 0.1664 & 0.1142 & 0.0233 & 0.0233 \\
$\Lambda$-Banzhaf N & 0.2588 & 0.2462 & 0.1541 & 0.1541 & 0.1541 & 0.0164 & 0.0164 \\
DPI & 0.2664 & 0.1680 & 0.1600 & 0.1600 & 0.1530 & 0.0464 & 0.0464 \\
PGI & 0.2234 & 0.1685 & 0.1612 & 0.1612 & 0.1538 & 0.0659 & 0.0659 \\
\hline Share of seats & 0.2533 & 0.2267 & 0.1733 & 0.1733 & 0.1200 & 0.0267 & 0.0267 \\
\hline
\end{tabular}

Table 4: Power indices in the 1986 Basque Parliament

We face now a 7-player game. As a consequence of the rise in the number of players, the power is much less concentrated. Again, the EFI is the index that gives the biggest share of power to the largest party (PSE), but this share is much smaller than it was in the previous election. Also, the PGI is once again the most distributive index, followed closely by the DPI. The Average index and the Banzhaf index are the ones that give the greatest amount of power to the second force, as happened in the first term.

The third, fourth and fifth terms of office bring similar patterns, with PNV dominating the game again and PSE (now united with EE), PP and the abertzale left parties (first HB and later EH) competing for the second place. Note that these parties represent the four corners of the board in relation with the left-right and center-periphery cleavages. Since we do not identify any new patterns in these terms, we skip to the sixth.

\subsubsection{Legebiltzarra}

PNV's candidate, Juna José Ibarretxe, who was already elected in 1998, was reelected by simple majority with the support of $\mathrm{PNV}(33)$ and IU-EB(3). He was the only candidate.

Table 5 shows the results for this term. The main change with respect to the previous terms is that UA did not get representation in the chamber, leading to a 6-player game. This increases the concentration of power in hands of PNV, who gets half the power according to the EFI.

At the opposite end, IU-EB, who wins a seat regarding the previous term, has no power according to the EFI and $\Lambda$-Banzhaf indices, and has very little also according to the Average index. 


\begin{tabular}{ccccccc}
\hline \hline Index $\backslash$ Party & PNV & PP & PSE-EE & EA & EH & IU-EB \\
\hline EFI & 0.5000 & 0.2500 & 0.0833 & 0.0833 & 0.0833 & 0 \\
Average & 0.4139 & 0.2264 & 0.1736 & 0.0847 & 0.0806 & 0.0208 \\
$\Lambda$-Banzhaf N & 0.3892 & 0.2513 & 0.1920 & 0.0838 & 0.0838 & 0 \\
DPI & 0.4722 & 0.1389 & 0.1056 & 0.1111 & 0.1056 & 0.0667 \\
PGI & 0.3390 & 0.1695 & 0.1356 & 0.1356 & 0.1356 & 0.0847 \\
\hline Share of seats & 0.3333 & 0.2533 & 0.1733 & 0.1067 & 0.0933 & 0.0400 \\
\hline
\end{tabular}

Table 5: Power indices in the 2001 Basque Parliament

We skip to the eighth term in order to show some considerations about the Average index.

\subsubsection{Legebiltzarra}

The term after the 2009 elections was the very only in the whole history of the Basque Parliament where a candidate not from PNV won the investiture. Patxi López, candidate of PSE-EE, defeated PNV's candidate Juan José Ibarretxe, who had been elected in the previous three terms, with the support of $\operatorname{PSE}-\mathrm{EE}(25), \operatorname{PP}(13)$ and $\operatorname{UPyD}(1)$, whose sum was enough to achieve the absolute majority.

\begin{tabular}{cccccccc}
\hline \hline Index $\backslash$ Parties & PNV & PSE-EE & PP & Aralar & EBB & EA & UPyD \\
\hline EFI & 0.6143 & 0.1976 & 0.1143 & 0.0310 & 0.0143 & 0.0143 & 0.0143 \\
Average & 0.4560 & 0.2665 & 0.2332 & 0.0165 & 0.0093 & 0.0093 & 0.0093 \\
$\Lambda$-Banzhaf N & 0.3838 & 0.3049 & 0.2786 & 0.0132 & 0.0065 & 0.0065 & 0.0065 \\
DPI & 0.6250 & 0.0625 & 0.0500 & 0.0375 & 0.0750 & 0.0750 & 0.0750 \\
PGI & 0.4324 & 0.1081 & 0.0541 & 0.0811 & 0.1081 & 0.1081 & 0.1081 \\
\hline Share of seats & 0.4000 & 0.3333 & 0.1733 & 0.0533 & 0.0133 & 0.0133 & 0.0133 \\
\hline
\end{tabular}

Table 6: Power indices in the 2009 Basque Parliament

It is surprising that PNV lost the voting given the huge proportion of power that the indices allocate to it. In fact, only the Average and the $\Lambda$-Banzhaf indices assign a power quota greater than 0.5 to the members of the winning coalition $\{\mathrm{PSE}-\mathrm{EE}, \mathrm{PP}, \mathrm{UPyD}$. The other four indices, instead, allocate more power to the members of the losing coalition $\{\mathrm{PNV}$, Aralar, EBB $\}$. The reason why there is such a concentration of power in the hands of PNV even though this is a 7-player game is that three of the players (EBB, EA and UPyD) have 
only one deputy in the chamber. Of course, these three players receive an identical share of power no matter what index we consider. It is interesting how these three players get equal or even better shares of power than PSE-EE and PP acording with DPI and PGI, given that, despite their small size, participate in at least as many minimal winning embedded coalitions than the middle sized parties.

\subsubsection{Legebiltzarra}

In 2012 elections PNV comes back to the government with Iñigo Urkullu, who is chosen by simple majority in the second round with the only support of its party (27). The abertzale left coalition EH-Bildu (21) proposed Laura Mintegi as an alternative candidate, but was only supported by her party. The rest of forces in the chamber, i.e., PSE-EE, PP and UPyD, abstained. The results are depicted in Table 7 .

\begin{tabular}{cccccc}
\hline \hline Index $\backslash$ Party & PNV & EH-Bildu & PSE-EE & PP & UPyD \\
\hline EFI & 0.5833 & 0.2500 & 0.0833 & 0.0833 & 0 \\
Average & 0.4333 & 0.2597 & 0.1764 & 0.0931 & 0.0375 \\
$\Lambda$-Banzhaf N & 0.4250 & 0.2550 & 0.1850 & 0.0850 & 0.0500 \\
DPI & 0.3939 & 0.2576 & 0.1667 & 0.1212 & 0.0606 \\
PGI & 0.2857 & 0.2857 & 0.1905 & 0.1429 & 0.0952 \\
\hline Share of seats & 0.3600 & 0.2800 & 0.2133 & 0.1333 & 0.0133 \\
\hline
\end{tabular}

Table 7: Power indices in the 2012 Basque Parliament

A main feature of the ninth term is the reduction of the parties represented in the chamber. We find now a 5-player game with a very small player, UPyD, that is powerless according to EFI. This index is also the only one that assigns equal power to PSEE-EE and PP.

\subsubsection{Legebiltzarra}

In the current term of office Iñigo Urkullu, candidate of PNV, was reelected (he had already been Lehendakari in the previous term) with the support of PNV(28) and PSE-EE(9). The other candidate was Maddalen Iriarte, from EH-Bildu, who only obtained the 18 votes from her party. 


\begin{tabular}{cccccc}
\hline \hline Index $\backslash$ Party & PNV & EH-Bildu & Podemos & PSE-EE & PP \\
\hline EFI & 0.5667 & 0.1500 & 0.1500 & 0.0667 & 0.0667 \\
Average & 0.4722 & 0.1806 & 0.1806 & 0.0833 & 0.0833 \\
$\Lambda$-Banzhaf N & 0.4100 & 0.2130 & 0.2130 & 0.0820 & 0.0820 \\
DPI & 0.4167 & 0.1667 & 0.1667 & 0.1250 & 0.1250 \\
PGI & 0.2800 & 0.2000 & 0.2000 & 0.1600 & 0.1600 \\
\hline Share of seats & 0.3733 & 0.2400 & 0.1467 & 0.1200 & 0.1200 \\
\hline
\end{tabular}

Table 8: Power indices in the 2016 Basque Parliament

In this term two of the traditional forces of the chamber, PSE-EE and PP, see how their number of seats sinks. EH-Bildu, that emerged in the previous term, consolidates as the second force. We have again a 5-player game, and for its simplicity EH-Bildu and Podemos are symmetric players in the game, even though they have a quite different number of seats. Of course, PSE-EE and PP, which have the same share of seats, are symmetric too.

\subsection{Evolution of the power by ideologies}

We now analyze the evolution of the power for each of the four corners of the political board. For each of these corners we have chosen one party that we think is the most representative: $\mathrm{PNV}$ for right-periphery, AP/PP for right-centre, PSE/PSE-EE for left-centre and $\mathrm{HB} / \mathrm{EH} /$ Aralar/EH-Bildu for left-periphery. ${ }^{19}$

It is important to have in mind that all the considered indices assume that all coalitions are feasible. However, it is clear that in reality some coalitions are unlikely (or even impossible) for ideological reasons.

\subsubsection{Right-Periphery}

PNV has been the hegemonic force in the Basque Parliament since its birth. It has been the main party of the chamber in 10 out of 11 terms of office and their candidates have won the investiture in another 10 .

\footnotetext{
${ }^{19}$ In the case of this last one, because of the ban of HB first and EH later, it has been impossible to take one single party. We have chosen these four because of their common origins and shared membership (Calvo, 2012).
} 


\section{Evolution of Indices for PNV}

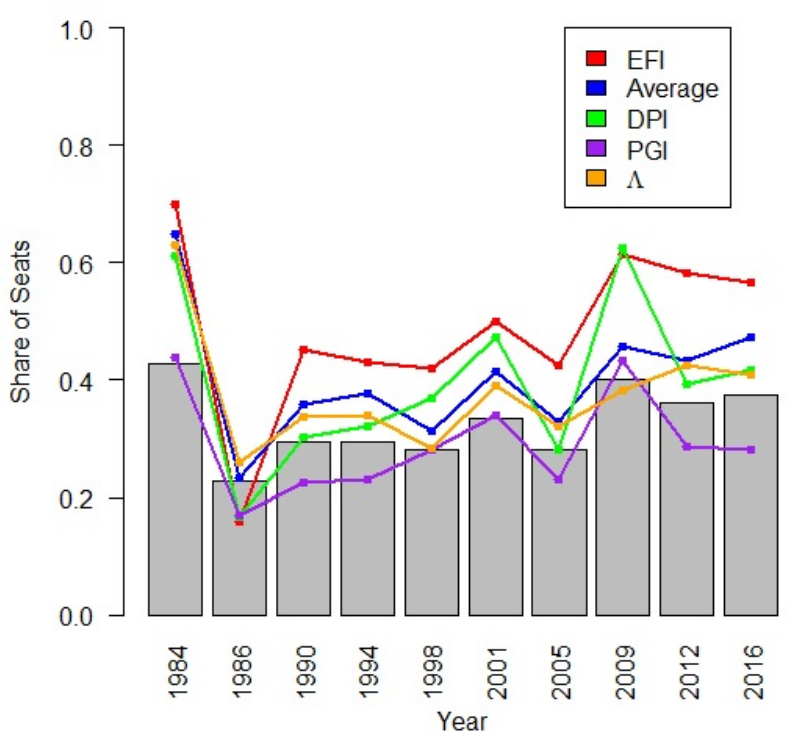

Figure 2: Evolution of the power of PNV

Figure 2 shows this hegemony: PNV gets a proportion of seats greater than 0.3 in every election, except for the year 1986. The power indices give this party a weight even greater than its seats proportion, with the exception of the PGI. As we have seen, this index is the most proportional one as it distributes the power more evenly.

The majoritarian feature of the EFI is glaring. Note that in the 1986 election, the only one in which PNV is not the first force of the chamber, this index falls dramatically. In the other hand, in the rest of the legislatures it is, by far, the highest index.

The $\Lambda$-Banzhaf, Average and Deegan-Packel indices occupy an intermediate place between the PGI and the EFI, and the three of them over represent the power of PNV.

In our opinion, this overestimation of PNV's power in relation with its proportion of seats shows how the investiture procedure employed in the Basque Parliament benefits the first force, as it gives it much more power than its share of seats. The dominance of almost all of the investitures exerted by PNV seems to confirm this idea. 


\subsubsection{Left-Center}

PSE has traditionally been the second force of the Basque Parliament, with some exceptions ${ }^{20}$ and it is the only party different from PNV that has managed to reach the presidency of the Basque Government.

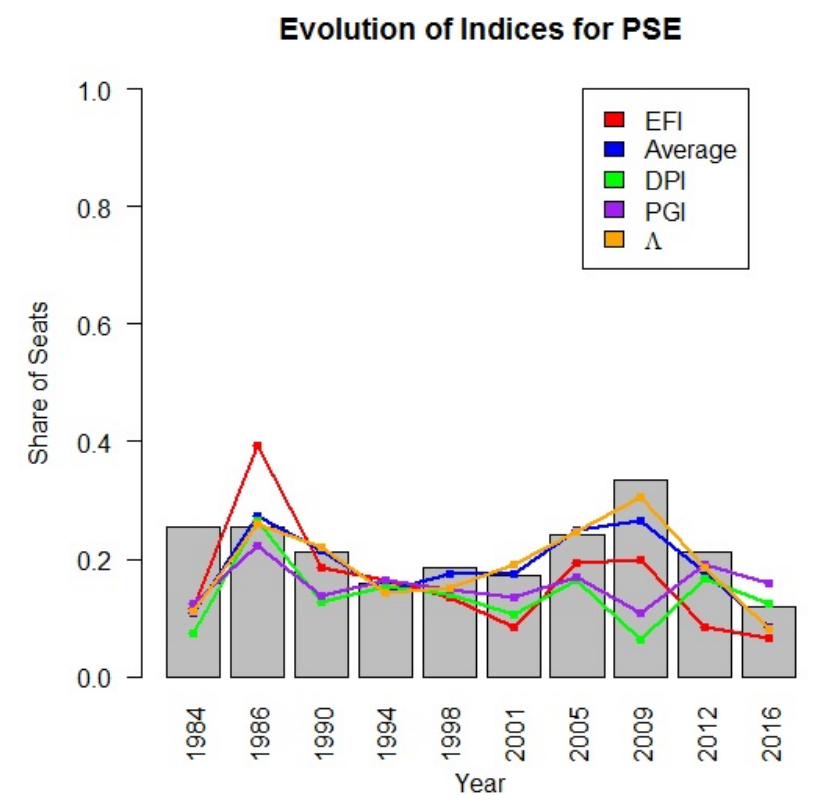

Figure 3: Evolution of the power of PSE

The Average index is the highest one overall. In the second term it is largely surpassed by the EFI, given that PSE becomes the biggest force in the chamber in 1986. In the last term PSE sinks to become, along with PP, the last force, and in consequence the PGI becomes the highest one and over represents the power of PSE due to its proportional nature.

\subsubsection{Left-Periphery}

The political history of the Basque Country cannot be understood without the role of the abertzale left, even before the democracy. The term refers to the nationalist stream born

\footnotetext{
${ }^{20}$ In the second, fifth, sixth, ninth and tenth legislatures.
} 
in the 50's as a leftist alternative to PNV, whose organizations share as common goals the independence and the socialism, even though they do not share the methods (Calvo, 2012).

However, the ban of the main abertzale left parties, namely Herri Batasuna, Euskal Herritarrok and PCTV, prevented them from playing a decisive role in the Basque Parliament. This fact is specially evident in the 2009 election, when the traditional abertzale trend linked with Batasuna asked their supporters to vote null instead of voting Aralar, who was ideologically close but condemned the armed conflict of ETA. However, from 2012 on, the emergence of EH-Bildu has made the abertzale left the second most influential force in the chamber, position that they keep holding nowadays.

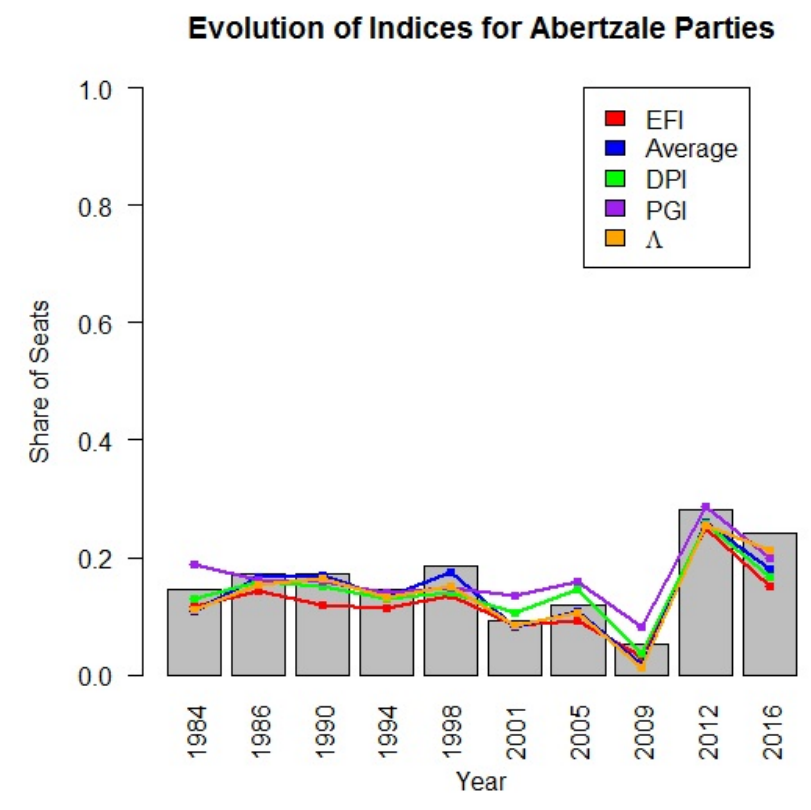

Figure 4: Evolution of the power of the abertzale left

Taking a look at Figure 4, the EFI is always between the lowest indices, given that the abertzale left has never managed to become the first force. The PGI is the one with the highest overall level, specially in the legislatures where the abertzale left got its worst results: 2001, 2005 and 2009. 


\subsubsection{Right-Center}

Although PP has been, alongside with PSOE, the dominant party of the Spanish political system since the transition to democracy, it has never been able to exercise such dominion in the Basque region. That does not mean that it has been irrelevant, as it has managed to compete effectively for the second place with PSE and the abertzale left, and it was part of a government coalition with PSE-EE in the year 2009.

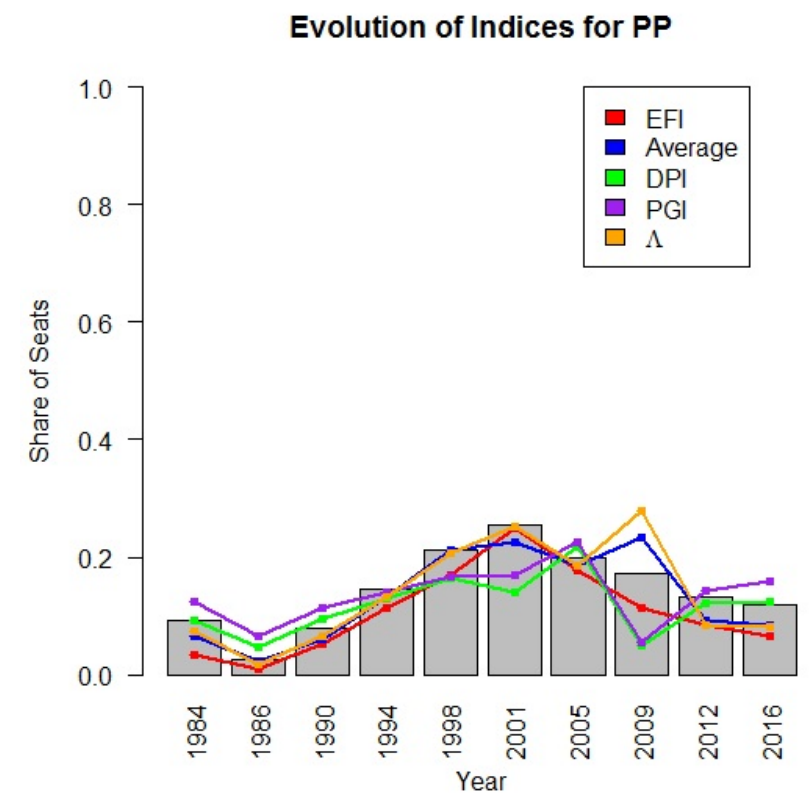

Figure 5: Evolution of the power of PP

As we can see in Figure 5, the PGI over represents the power of PP in the legislatures where it gets bad results $(1984,1986,2012$ and 2016). The DPI values are very close to these.

Instead, the Average index and the EFI show low shares of power in these legislatures, but a remarkable growth in those where PP is the second or third force of the chamber (1994-2009). This is particularly true for the Average index. The growth of the $\Lambda$-Banzhaf index in the sixth term (2001) is remarkable. At that term PP got its best results, becoming the second force with 19 seats, 6 more than the PSE-EE.

Looking back we can see that the PGI is the only one that over represents the small 
forces, while the other four tend to over represent the first force, which is specially dramatic in the case of the EFI.

\section{Conclusions}

To start with, we have seen that incorporating externalities to classic simple games allows us to study the distribution of power more accurately in some situations. We have applied five recently proposed power indices for games with externalities to a real example to explore their usefulness. Below, we describe the main observed trends of the these indices, which can be divided in two families.

On the one hand, we focus on the three indices that generalize the most popular power indices, namely the Shapley-Shubik and Banzhaf indices. The Externality-free index seems to be the one that rewards the most the largest party of the chamber. The Average index is the one that gives more power to the second largest party in most cases. The behavior of the normalized $\Lambda$-Banzhaf index is quite similar to the Average index and it seems that the probability distribution that we have estimated from the ideological positions has not added much value to the analysis.

On the other hand, the two indices that only use minimal winning coalitions show quite different power distributions from the other three. In general, they distribute the power much more evenly. This behavior is in line with the classic indices that they extend. The DP-Index is less proportional than the PGI-Index and many times is closer to the indices of the other family.

The main conclusion that we can draw from our analysis is that the Basque investiture procedure, based on a plurality rule, favors the dominance of the biggest party. This feature has allowed PNV to remain the dominant force of the system. In general terms, the real power of the largest party is higher than its share of seats, we consider this an evidence of a deeply majoritarian investiture procedure. In addition, in most cases the power of small parties is lower than their proportion of seats.

So far, the voting procedure has eased the governability in a deeply fragmented political system, where a great number of political forces have managed to get representation. However, we can observe that the number of competing parties tends to reduce in the last two 
legislatures. The reduction of the fragmentation may open the debate whether this system continues to be necessary.

In the future, we would like to incorporate restrictions to the cooperation among parties in order to evaluate their impact. For instance, in some cases parties have clearly stated that they will not collaborate with other parties. This opens the door to restrict the coalitions that we use to compute the power indices. Similarly, we would like to use the identified positions of the parties in the two dimensional ideological space to compute some spatial power indices. Our purpose is to compare the power distributions in each of these models and determine what model describes the reality more faithfully, if any.

\section{Acknowledgement}

The second author acknowledges the support from the European Regional Development Fund (ERDF) and Ministerio de Economía, Industria y Competitividad through grant ECO201786481-P and from Generalitat de Catalunya through grant 2017-SGR-778.

\section{References}

Albertos, J. F. (2002). Votar en dos dimensiones: el precio del nacionalismo y la ideología en el comportamiento electoral vasco, 1993-2001. Revista Española de Ciencia Política, $6: 153-181$.

Alonso-Meijide, J. M., Álvarez-Mozos, M., and Fiestras-Janeiro, M. G. (2017a). Power indices and minimal winning coalitions for simple games in partition function form. Group Decision and Negotiation, 26(6):1231-1245.

Alonso-Meijide, J. M., Álvarez-Mozos, M., Fiestras-Janeiro, M. G., and Jiménez-Losada, A. (2017b). Some structural properties of a lattice of embedded coalitions. International Journal of General Systems, 46(2):123-143.

Alonso-Meijide, J. M. and Bowles, C. (2005). Generating functions for coalitional power indices: An application to the IMF. Annals of Operations Research, 137(1):21-44.

Álvarez-Mozos, M., Alonso-Meijide, J. M., and Fiestras-Janeiro, M. G. (2017). On the externality-free Shapley-Shubik index. Games and Economic Behavior, 105:148-154. 
Álvarez-Mozos, M. and Tejada, O. (2015). The Banzhaf value in the presence of externalities. Social Choice and Welfare, 44:781-805.

Ansolabehere, S. and Puy, M. (2015). Ideology, nationalism, and identity in Basque regional elections. Technical report, Universidad de Málaga, Department of Economic Theory, Málaga Economic Theory Research Center.

Arévalo-Iglesias, G. (2018). Values for games with externalities. Master's thesis, University of Santiago de Compostela.

Banzhaf, J. F. (1964). Weighted voting doesn't work: A mathematical analysis. Rutgers Law Review, 19:317.

Calvo, R. L. (2012). Izquierda abertzale: De la heterogeneidad al monolitismo. In Coetánea: III Congreso Internacional de Historia de Nuestro Tiempo, pages 377-388. Universidad de La Rioja.

Casajus, A. (2012). Amalgamating players, symmetry, and the Banzhaf value. International Journal of Game Theory, 41(3):497-515.

de Clippel, G. and Serrano, R. (2008). Marginal contributions and externalities in the value. Econometrica, 76(6):1413-1436.

De la Calle Robles, L. (2005). Cuando la proximidad deja de ser importante: modelos espaciales y voto en la política vasca (1994-2001). Revista Española de Ciencia Política, $12: 21-52$.

Deegan, J. and Packel, E. (1978). A new index of power for simple $n$-person games. International Journal of Game Theory, 7(2):113-123.

Dubey, P. (1975). On the uniqueness of the Shapley value. International Journal of Game Theory, 4(3):131-139.

Dubey, P. and Shapley, L. S. (1979). Mathematical properties of the Banzhaf power index. Mathematics of Operations Research, 4(2):99-131.

Gillespie, R. (2000). Political polarization in the Basque Country. Regional $\& 5$ Federal Studies, 10(1):112-124.

Haller, H. (1994). Collusion properties of values. International Journal of Game Theory, 23(3):261-281. 
Holler, M. J. (1982). Forming coalitions and measuring voting power. Political Studies, $30(2): 262-271$.

Holler, M. J. and Packel, E. W. (1983). Power, luck and the right index. Journal of Economics, 43:21-29.

Huber, G., Kocher, M., and Sutter, M. (2003). Government strength, power dispersion in governments and budget deficits in OECD-countries. A voting power approach. Public Choice, 116(3-4):333-350.

Knutsen, O. (1995). Value orientations, political conflicts and left-right identification: A comparative study. European Journal of Political Research, 28(1):63-93.

Laruelle, A. and Widgrén, M. (1998). Is the allocation of voting power among EU states fair? Public Choice, 94(3-4):317-339.

Leonisio, R. (2012). Parliament on the centre-right, government on the left: Explaining Basque exceptionalism. Regional \&f Federal Studies, 22(1):45-60.

Leonisio, R. and Strijbis, O. (2014). Beyond self-placement: Why nationalism is a better predictor of electoral behaviour in the Basque Country. Revista Española de Investigaciones Sociológicas, 146:47-68.

Macho-Stadler, I., Pérez-Castrillo, D., and Wettstein, D. (2007). Sharing the surplus: an extension of the Shapley value for environments with externalities. Journal of Economic Theory, 135(1):339-356.

Maskin, E. (2016). How can cooperative game theory be made more relevant to economics?: An open problem. In Open Problems in Mathematics, pages 347-350. Springer.

Penrose, L. S. (1946). The elementary statistics of majority voting. Journal of the Royal Statistical Society, 109(1):53-57.

Shapley, L. S. (1953). A value for n-person games. In Tucker, A. W., editor, Contributions to the Theory of Games II, pages 307-317. Princeton University Press.

Shapley, L. S. and Shubik, M. (1954). A method for evaluating the distribution of power in a committee system. American Political Science Review, 48(3):787-792.

Straffin, P. D. (1988). The Shapley-Shubik and Banzhaf power indices as probabilities. In Roth, A. E., editor, The Shapley Value. Essays in honor of Lloyd S. Shapley, pages 71-81. Cambridge University Press. 
Thrall, R. and Lucas, W. (1963). n-person games in partition function form. Naval Research Logistics Quarterly, 10(1):281-298.

Van der Eijk, C., Schmitt, H., and Binder, T. (2005). Left-right orientations and party choice. In The European Voter, pages 167 - 191. Oxford University Press.

Young, H. P. (1985). Monotonic solutions of cooperative games. International Journal of Game Theory, 14(2):65-72. 